\title{
Application of Variational Analysis of Wind Field Based on Lidar Conical Scans to Air Quality Monitoring
}

\author{
P.W. Chan ${ }^{1}$ and Frank $\mathrm{Yu}^{*}, 2$ \\ ${ }^{1}$ Hong Kong Airport Observatory, Hong Kong \\ ${ }^{2}$ Department of Environment and Conservation, Western Australia
}

\begin{abstract}
Conical scans of Doppler LIDAR were made at a specific elevation angle to monitor the wind fields in cases of plume dispersion in western Australia. To better visualize the airflow patterns in relation to the plume direction, variational analysis is performed on the radial velocity data of the LIDAR to retrieve the $2 \mathrm{D}$ wind fields. Compared to the 4DVAR method, the 2D variational analysis as adopted in the present paper is computationally more efficient yet provides sufficient details of the flow patterns. Examples of the plume dispersion are shown with the $2 \mathrm{D}$ analyzed wind fields as presented in the paper. In general, the analyzed wind fields are consistent with the plume directions as observed from the backscattered power data of the LIDAR.
\end{abstract}

Keywords: LIDAR, 2D wind retrieval, sodar, air quality monitoring.

\section{INTRODUCTION}

A 2D wind retrieval algorithm developed for the Hong Kong International Airport [1] is used to derive the wind field from the Doppler LIDAR conical scans for an analysis of the plume dispersion at the Wagerup air quality monitoring experiment in Western Australia in 2006. The radial velocity data obtained from Doppler LIDAR scans are not straightforward for an interpretation of the wind vectors for relating to the plume dispersion. It would be quite handy to have the full wind vectors overlaid on top of the radial velocity data to assist the analysis of the wind dynamics and the dispersion mechanism. The $2 \mathrm{D}$ wind retrieval method is computationally more efficient than the four dimensional variational (4DVAR) LIDAR data analysis [2, 3].

Two cases (on $18^{\text {th }}$ and $29^{\text {th }}$ August 2006) are selected for testing the 2D wind retrieval algorithm in different meteorological conditions to show the capability and efficiency in providing wind vector overlays on the LIDAR scanning cones. The $2 \mathrm{D}$ wind retrieval technique based on a variational method is described in the next section and the comparisons with available point measurements are given in Section 3. Details regarding plume dispersion and wind dynamics are discussed in Section 4. The conclusions are given in Section 5.

\section{2D VARIATIONAL WIND RETRIEVAL METHOD}

Details of the retrieval method are given in [1]. Only a summary of the major steps of the method are mentioned here. The cost function $J$ to be minimized is given by:

$$
\begin{aligned}
J(u, v)= & J_{1}+J_{2}+J_{3}+J_{4}+J_{5}+J_{6} \\
=\sum_{i, j}\left\{W_{1}\right. & {\left[\left(u-u_{B}\right)^{2}+\left(v-v_{B}\right)^{2}\right]+W_{2}\left(v_{r}-v_{r}^{o b s}\right)^{2}+W_{3}\left(\frac{\partial u}{\partial x}+\frac{\partial v}{\partial y}\right)^{2}+W_{4}\left(\frac{\partial v}{\partial x}-\frac{\partial u}{\partial y}\right)^{2} } \\
& \left.+W_{5}\left(\nabla^{2} u+\nabla^{2} v\right)^{2}+\sum_{n}\left[W_{6}\left(\frac{\partial v_{r}^{o b s}}{\partial t}+u \frac{\partial v_{r}^{o b s}}{\partial x}+v \frac{\partial v_{r}^{o b s}}{\partial y}\right)^{2}\right]\right\} .
\end{aligned}
$$

*Address correspondence to this author at the Department of Environment and Conservation, 17 Dick Perry Ave., Kensington, WA 6151, Western Australia; Tel: (852) 2926 8435; Fax: (852) 2375 2645;

E-mail: frank.yu@dec.wa.gov.au where $u$ and $v$ are the components of the retrieved wind field, subscript $B$ the background field (generated from LIDAR radial velocity in the way described in [4], $v_{r}$ the retrieved radial velocity, superscript $o b s$ the observed values, $i$ and $j$ the horizontal grid point and $n$ the time index (three consecutive scans are used in each analysis). The weights are: $W_{1}=0.1$ (after the first step retrieval), $W_{2}=1, W_{3}=W_{4}$ $=W_{5}=0.1$ and $W_{6}=10^{4}$. They are chosen empirically in this paper to ensure that the constraints have proper orders of magnitude.

\section{COMPARISON WITH THE AVAILABLE SODAR AND ANEMOMETER MEASUREMENTS}

The LIDAR in use in the present paper has a wavelength of 2 microns. It has a spatial resolution of about $100 \mathrm{~m}$. PPI scans are updated every few minutes.

Wind measurements from other available instruments have been collected at the same time when the LIDAR performed its scanning at Wagerup (Fig. 1), a suburb located south of Perth near $20 \mathrm{~km}$ away from the coast of the Western Australia. There were five anemometers and a sodar placed around the LIDAR at the same period of time with most of them situating at the eastern side. An aluminum refinery plant is located right to the north of the anemometer AnaE and at about $1.5 \mathrm{~km}$ to the eastern side of LIDAR. LIDAR was placed temporarily on an elevated flat platform and the surrounding view is clear while LIDAR scans at an elevation angle above 2.5 degrees. Any scanning elevation angle below 2.5 degrees can be blocked by tall trees and other hard objects at the eastern, south-eastern and the northern side of the Lidar. Time series of continuous Planposition Indicator (PPI) LIDAR scans at 2.5 degree elevation angle are used for processing through the $2 \mathrm{D}$ wind field retrieval algorithm, and the wind vectors intersecting the verticals of all available sodar and anemometers are extracted for comparison.

The 2D wind vector retrieved from the LIDAR data are compared with the sodar measurements (wind speed and wind direction). Good agreement between the LIDAR- 


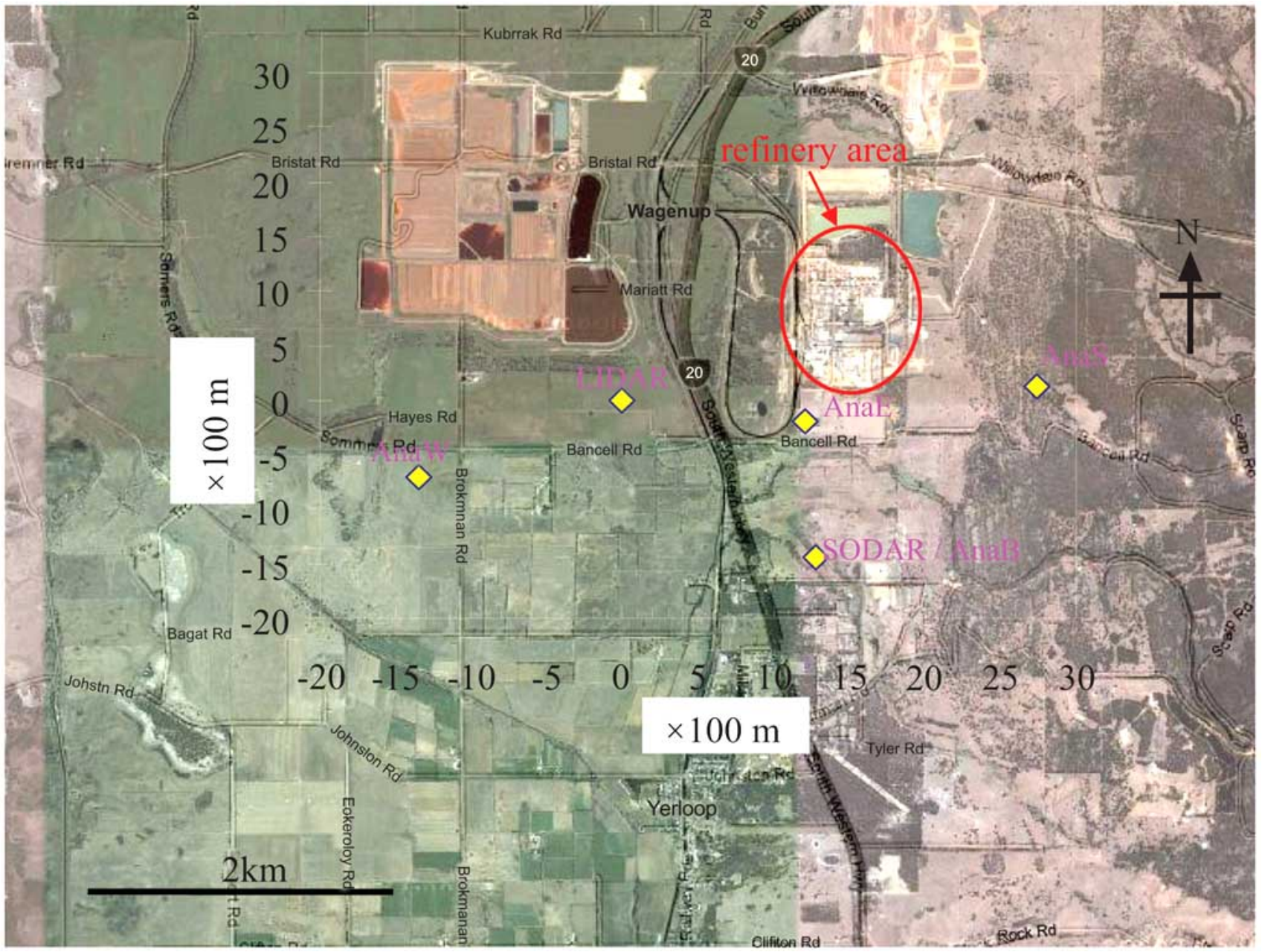

Fig. (1). Map of Wagerup suburb in Western Australia. The locations of the instruments are labeled. LIDAR is placed in a flat terrain next to the highway and other instruments are scattered around. (AnaW, AnaE, AnaS, AnaB are the locations of various anemometers. SODAR is the location of the sodar).

analyzed and the sodar measured wind speed and direction are shown on $29^{\text {th }}$ of August between 3 a.m. and 9 a.m. (Fig. 2) even that the comparison is not exact in terms of the sampling time and space. The 2D algorithm retrieved wind vector is compared to the wind vectors at the two different levels of the sodar. In addition to the spatial difference in comparison, there is also time averaging difference in sodar data (15 minutes) and LIDAR data (basically instantaneous). The 2D wind retrieval algorithm processes through the full PPI scans collected around a minute, which is much less than the sodar data averaging time. Deviation in wind direction increases as shown in Fig. (2b) around 6 a.m. when the horizontal wind weakened and turned to have westerly component. Similar results are obtained from the analysis on $18^{\text {th }}$ of August (not shown). In that case, the wind speed is also slightly higher for the LIDAR-retrieved winds when comparing to the sodar measurements (not shown). The comparison is not so good on $18^{\text {th }}$, probably due to the greater variation of the wind direction with height in the first hundred metre above ground on $18^{\text {th }}$ when comparing with the wind direction profile on $29^{\text {th }}$ August (Fig. 3).
The $2 \mathrm{D}$ wind vectors retrieved from the LIDAR are compared with the anemometer measurements (wind speed and wind direction). Comparisons to anemometer measurements are not as good as expected due to the large difference in altitude $(>50 \mathrm{~m})$ and the inherent difference between LIDAR and anemometers measurements (length of range gate of $\sim 100 \mathrm{~m} v s$ basically point measurement). The only anemometer that has less than $50 \mathrm{~m}$ difference in altitude is the AnaE located at the eastern wing of the LIDAR (location in Fig. 1). Comparisons on both days between $2 \mathrm{D}$ analysis results and AnaE readings are still quite satisfactory. Larger difference appears in wind direction during the wind direction transition when the lower level wind rotates (Fig. 4). The rotation of the lower level wind also appears in the sodar measurements $(67 \mathrm{~m}$ level at around 7 a.m. on $18^{\text {th }}$ and 6 a.m. on $29^{\text {th }}$ of August, Fig. 5) and, at the same time, the wind speeds drop. The rotation of the lower level wind observed by both LIDAR and sodar of the decoupled lower surface layer, at the time when the lower level strong inversion appears (with a height of about a hundred metre, see the potential temperature profiles in 
(a)

Wind Speed Comparison / 29 Aug 2006

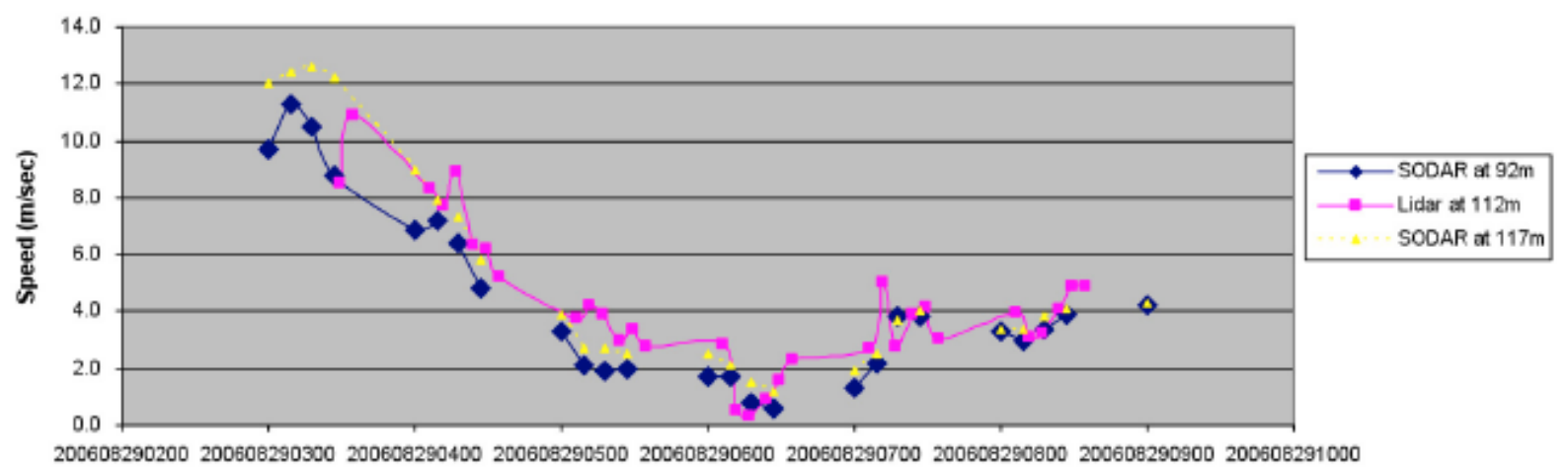

Time

(b)

Wind Direction Comparison / 29 Aug 2006

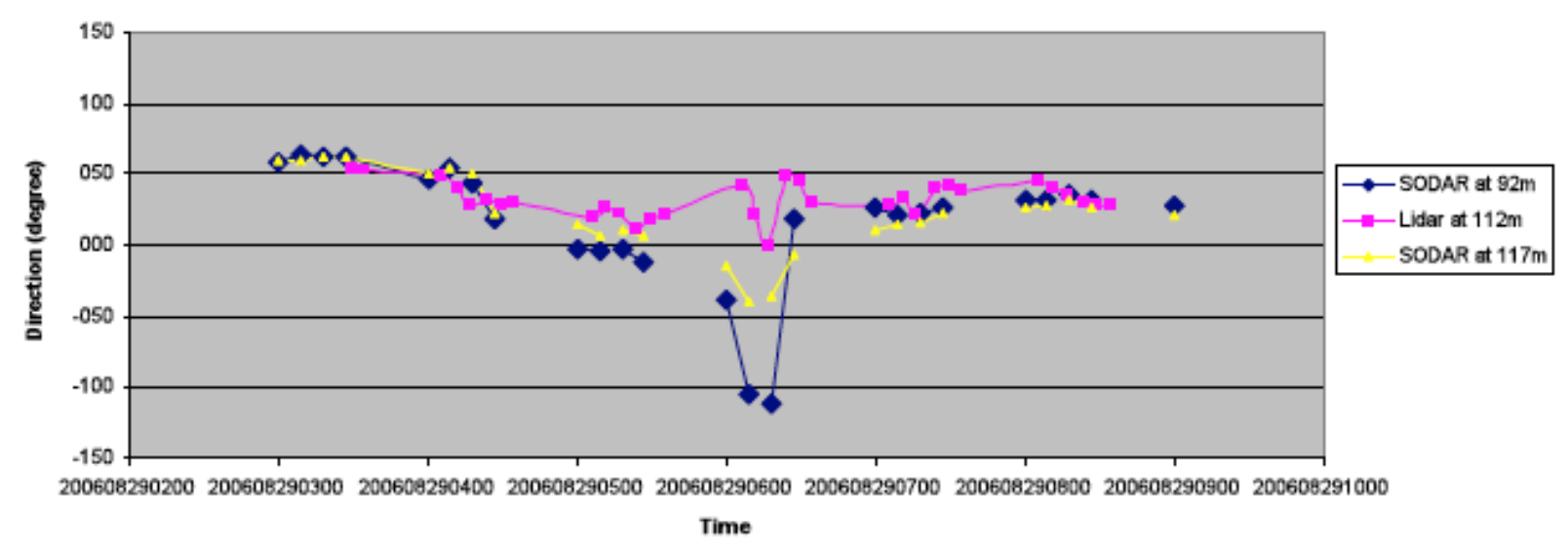

Fig. (2). Comparison of the 2D LIDAR algorithm-retrieved wind speed and direction with sodar measurements on 29 August 2006. Altitudes of the measurements are labeled in the legends.

Fig. 3), is likely linked to the blocking of sea-breeze-like front from the west southwest of Wagerup by the escarpment at the eastern side of LIDAR. Further investigation is required to be made in the future to understand the formation mechanism of such phenomenon.

\section{CONSISTENCY OF THE 2D WIND FIELD AND PLUME DISPERSION}

Time series of the wind vectors are derived by the $2 \mathrm{D}$ algorithm on both $18^{\text {th }}$ and $29^{\text {th }}$ of August. Examples of the analyzed results are given in Figs. $(6,7)$ to display the consistency of the wind field and the dispersion of the smoke plumes on the PPI cones. The smoke plumes are based on backscattered power data of the LIDAR. From the wind vector field shown, either half an hour or an hour apart, the rotation of the overall wind field can be observed. On $18^{\text {th }}$ during the presented hours (4:33 a.m. 7:05 a.m.), the overall wind direction slowly changes from northeasterly to northerly with the lower level winds blowing in nearly opposite directions around the LIDAR at about 5:49 a.m. and 6:39 a.m. The lower level wind changes also appear on the radial velocity plots with the negative radial wind components appearing at the western side of LIDAR. As discussed in Section 3, this change of wind direction may be related to the decoupling between the lower surface layer and the layer aloft. The reasons for the occurrence of this decoupling require further study.

The superimposed plots of the smoke plumes on the wind vectors field seem to follow the wind direction quite well. Especially for the plot shown at 6:39 a.m., it is clearly exhibited that the smoke aggregated right at the location where the wind flow actually converges at the southwestern side of LIDAR. Plumes near stacks drift more to the left by the lower level easterly component at the same time compared with the plume dispersions at the earlier times. At 7:05 a.m., the northerly winds prevail over eastern side of the LIDAR and the smoke plume spreads further southwards. During the measurement campaign, NOx measurements were collected continuously next to the sodar site (location in Fig. 1). At the downstream location of plumes around this particular time, we have also detected a peak of the higher NOx concentrations (Fig. 8a). 
(a)
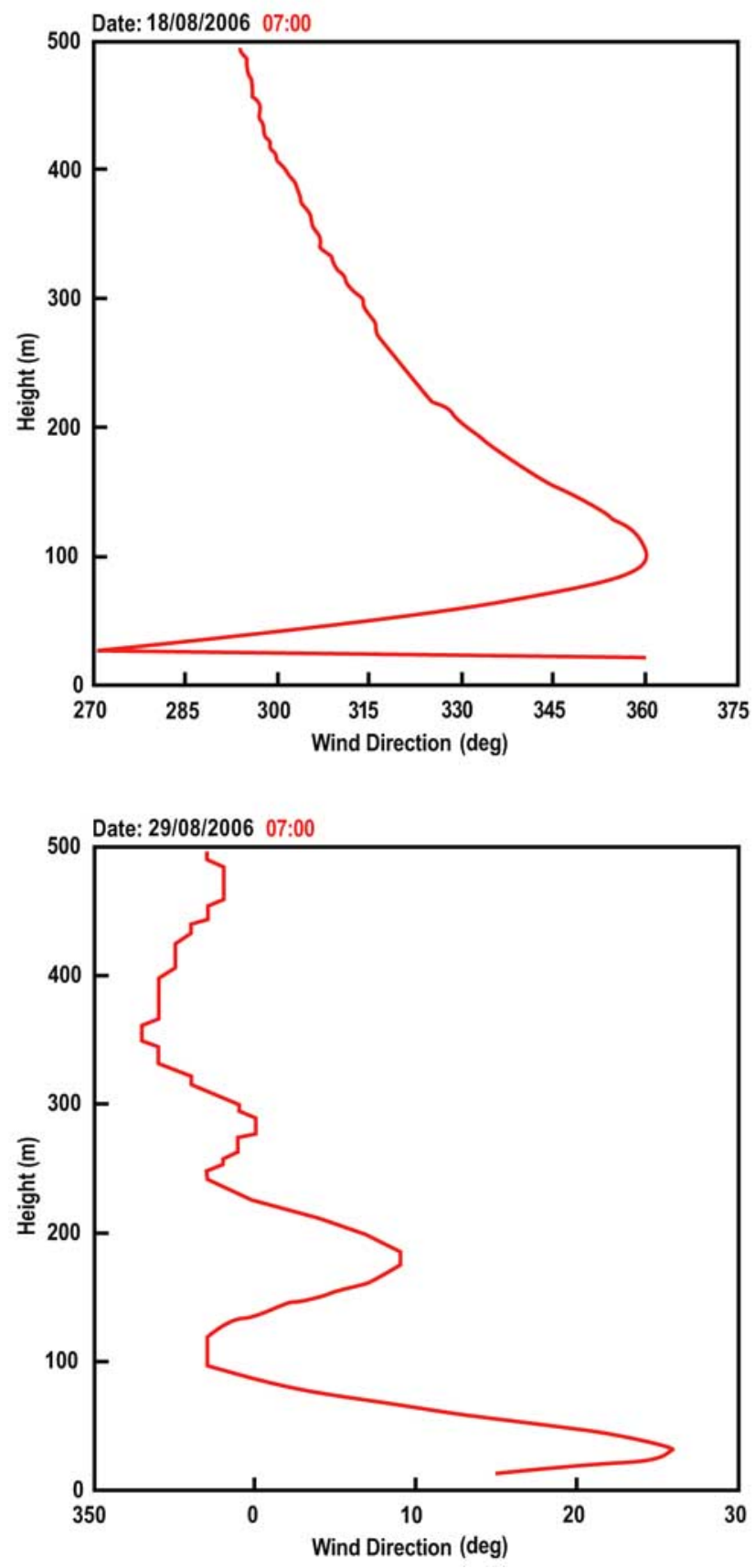

(b)
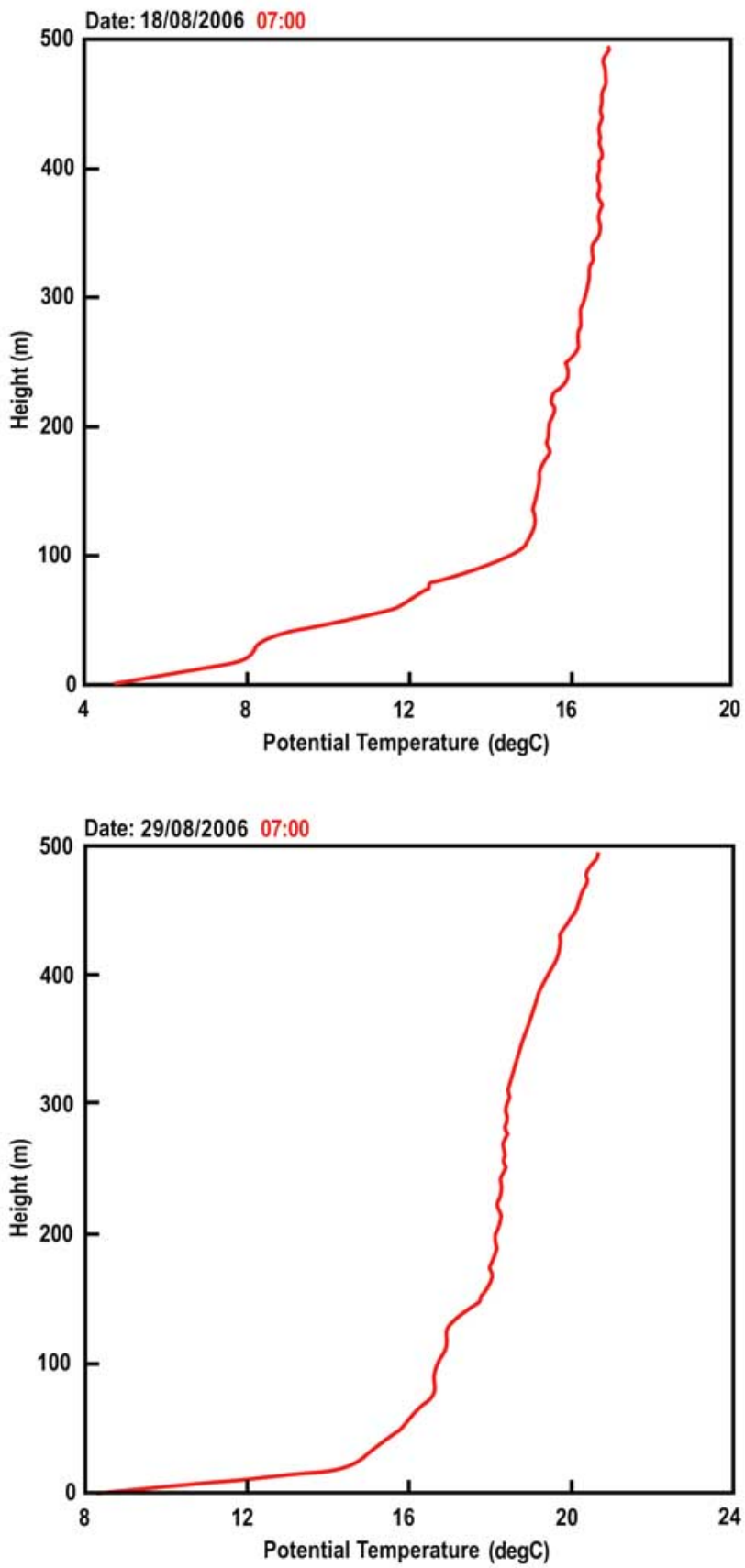

Fig. (3). Wind direction (a) and potential temperature (b) vertical profiles from radiosonde measurements on both $18^{\text {th }}$ and $29^{\text {th }}$ August 2006 .

On $29^{\text {th }}$, the tail of the smoke plumes extended longer for more than $6 \mathrm{~km}$ by the stable north to northeasterly. It is shown that the overall wind field slightly rotates during 4:29 a.m. to 5:50 a.m. from northeasterly to northerly. The superimposed smoke plumes appear to follow the advection of the wind well on the plots except for the last plot $(5: 50$ a.m.) around the tail of the plumes (Fig. 7). The mismatch is possibly caused by the lack of LIDAR data points after noise filtering of the velocity data at the longer ranges. Smoke appearing at the northern side of the LIDAR in Fig. (7) at about 5:50 a.m. is likely coming from the stacks due to the reverse south-westerly at the lower level. The smoke at the western side of the LIDAR at that time is due to the burning events at the farm area.

Again, around 5:00 a.m. $\sim$ 6:00 a.m., the NOx measurements are slightly higher than the average as shown in Fig. (8b). During this hour, the plume tail appeared in Fig. (7) extends across the location where NOx measurements were made (same location of measurement as the previous case). 
AnaE anemometer wind speed / 29 August 2006

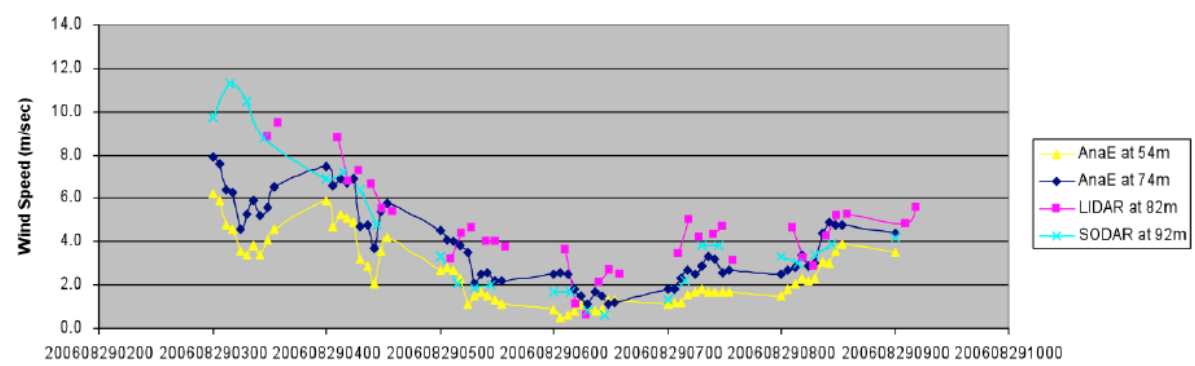

Time

AnaE anemometer wind directions / 29 August 2006

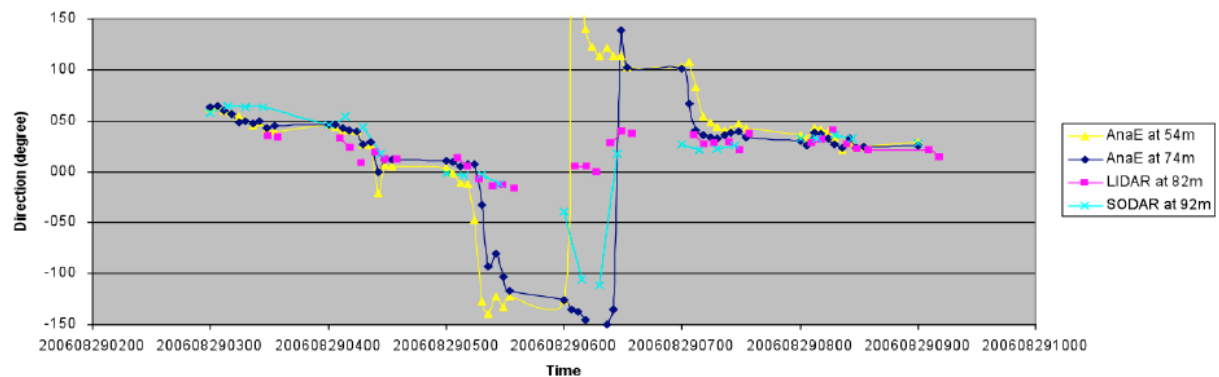

Fig. (4). AnaE anemometer wind speed and direction on 29 August 2006.

(a)

SODAR wind directions / 18 Aug 2006

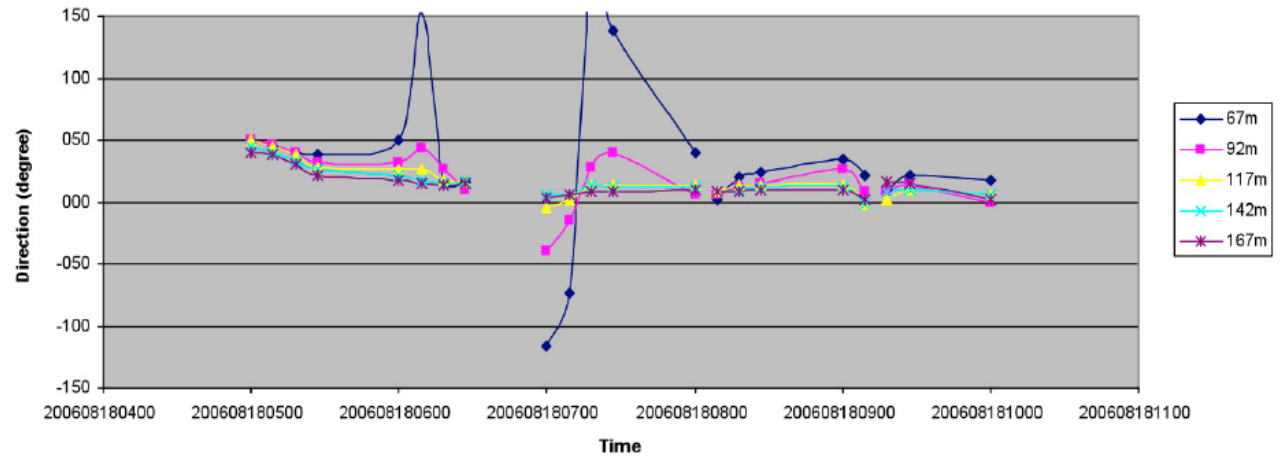

(b)

SODAR wind directions / 29 Aug 2006

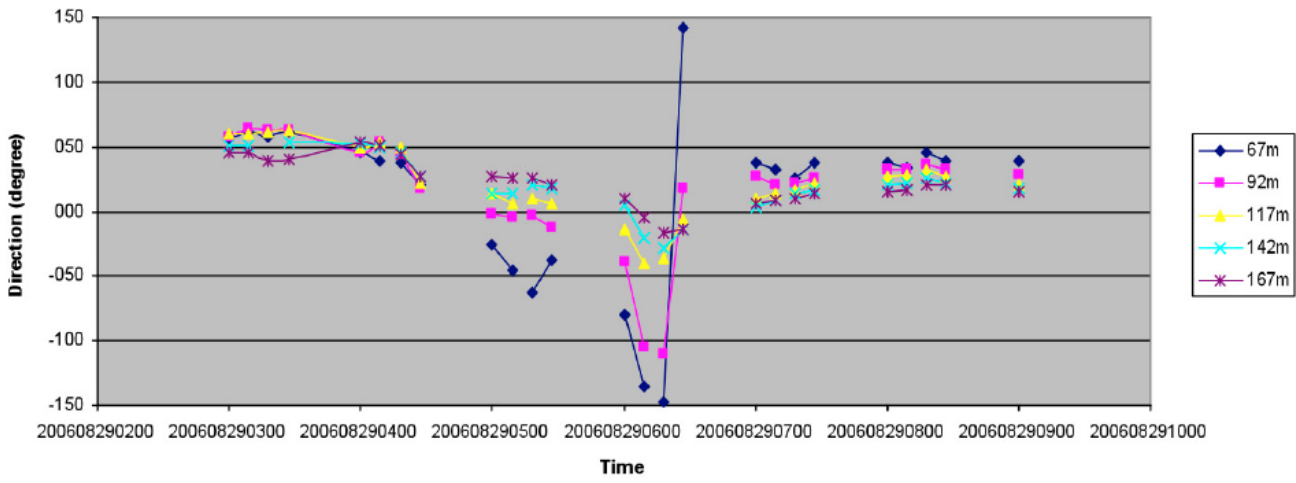

Fig. (5). Sodar wind directions at different heights on $18^{\text {th }}$ and $29^{\text {th }}$ August 2006. 

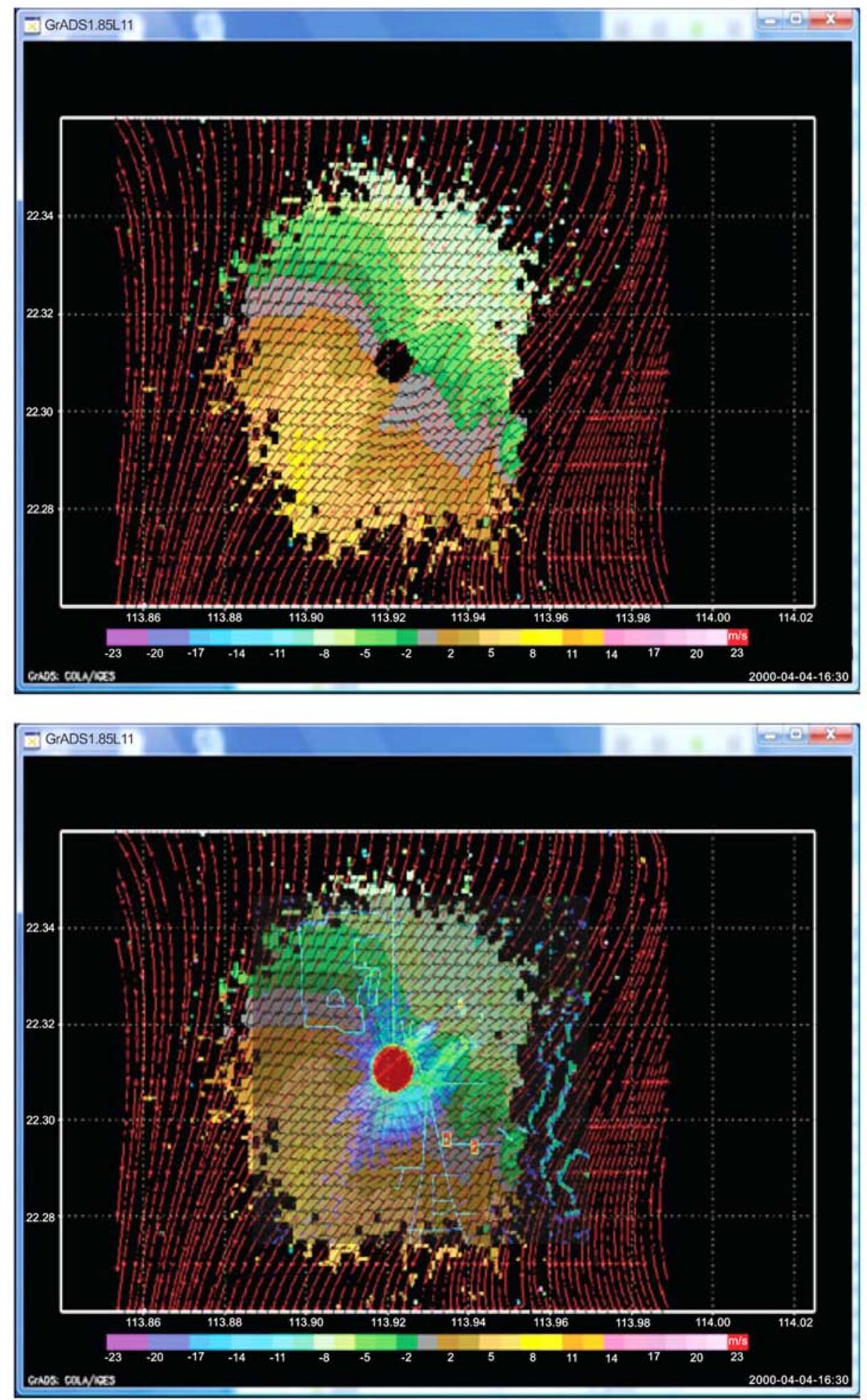

\section{4:33am, $18^{\text {th }}$ August}



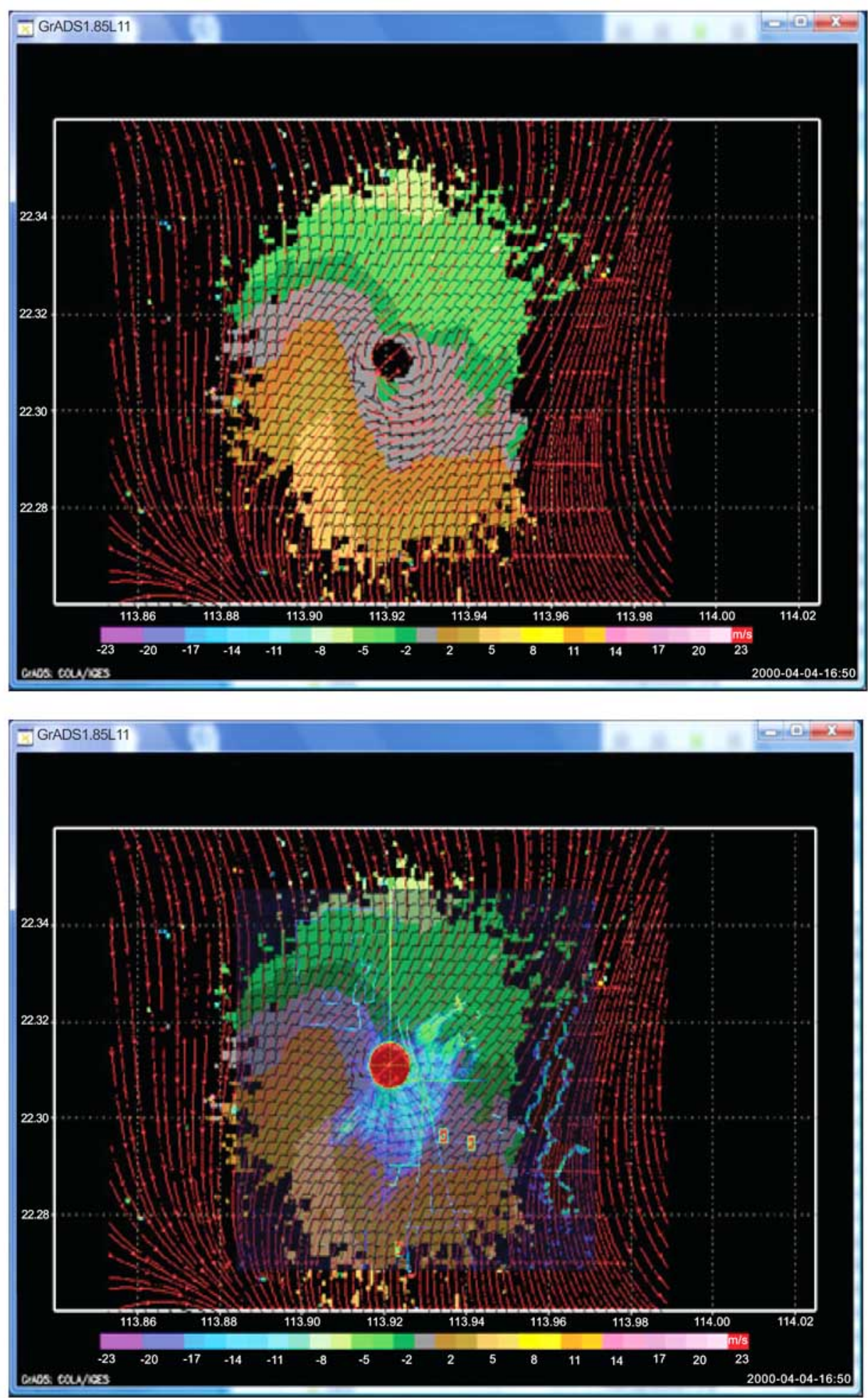

5:49am, $18^{\text {th }}$ August 
(Fig. 6) contd.....
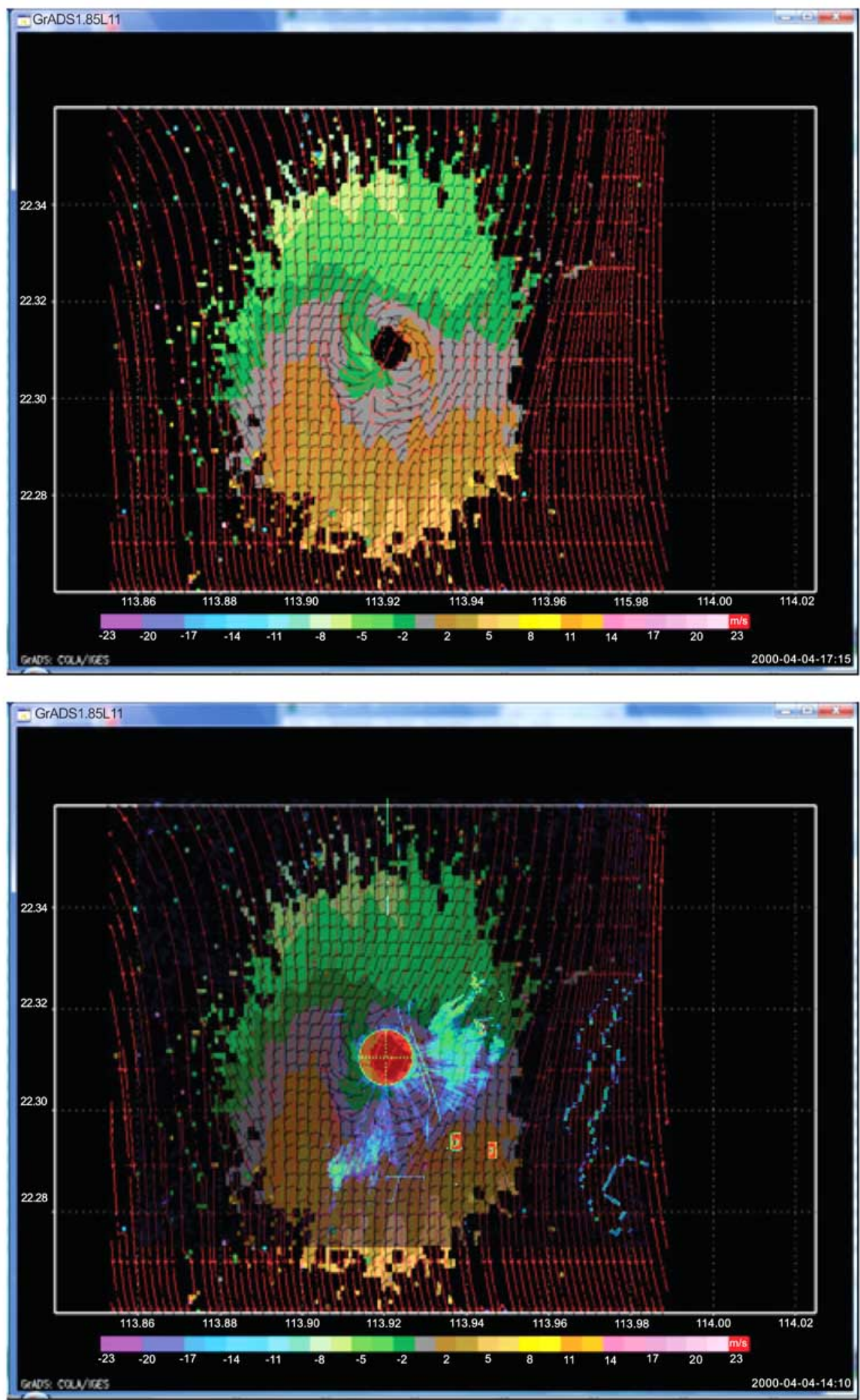

6:39am, $18^{\text {th }}$ August 
(Fig. 6) contd.....
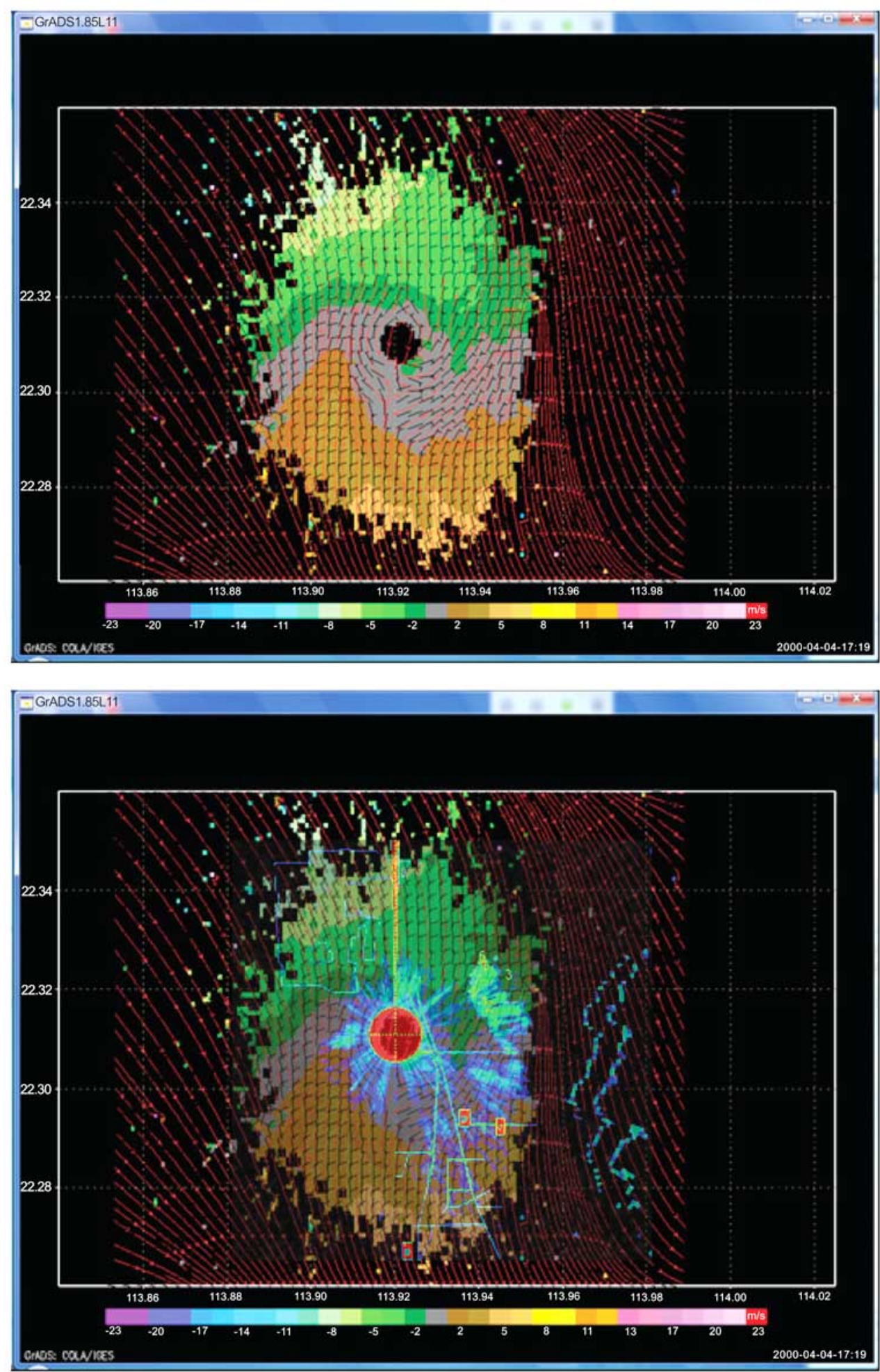
(Fig. 6) contd....

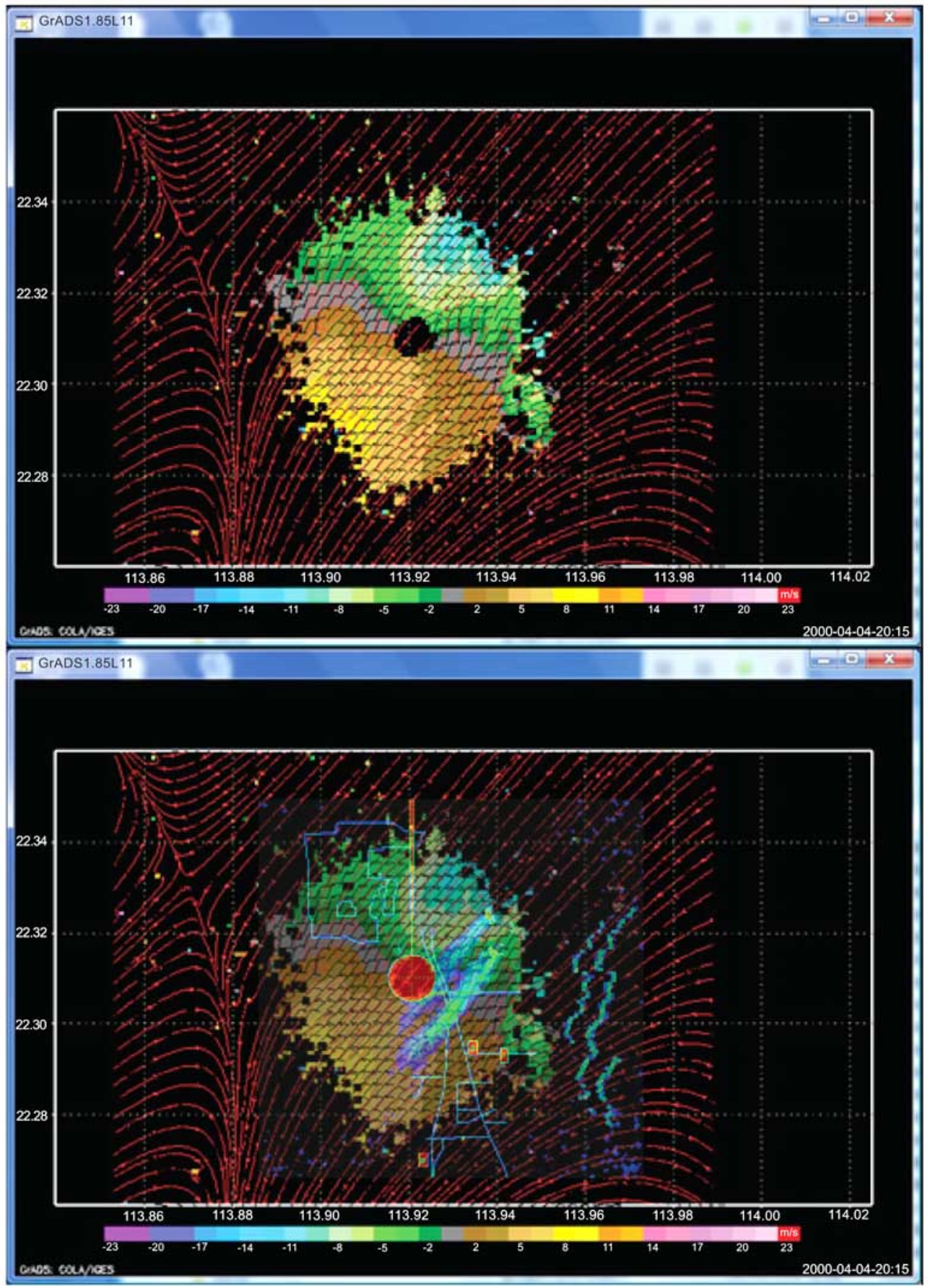

4:29am, $29^{\text {th }}$ August

Fig. (6). The time series of the wind field retrieved with the 2D LIDAR algorithm for the 18th of August. For each time two plots are shown. The first plot shows colour contour of the radial velocity measured by LIDAR superimposed to the wind vector streamline given in red. The black wind barbs represent individual vectors retrieved by the $2 \mathrm{D}$ algorithm. The dotted boxes have a size of about $2 \mathrm{~km}$ by $2 \mathrm{~km}$. The second plot is equal to the first one with the smoke plumes superimposed. 


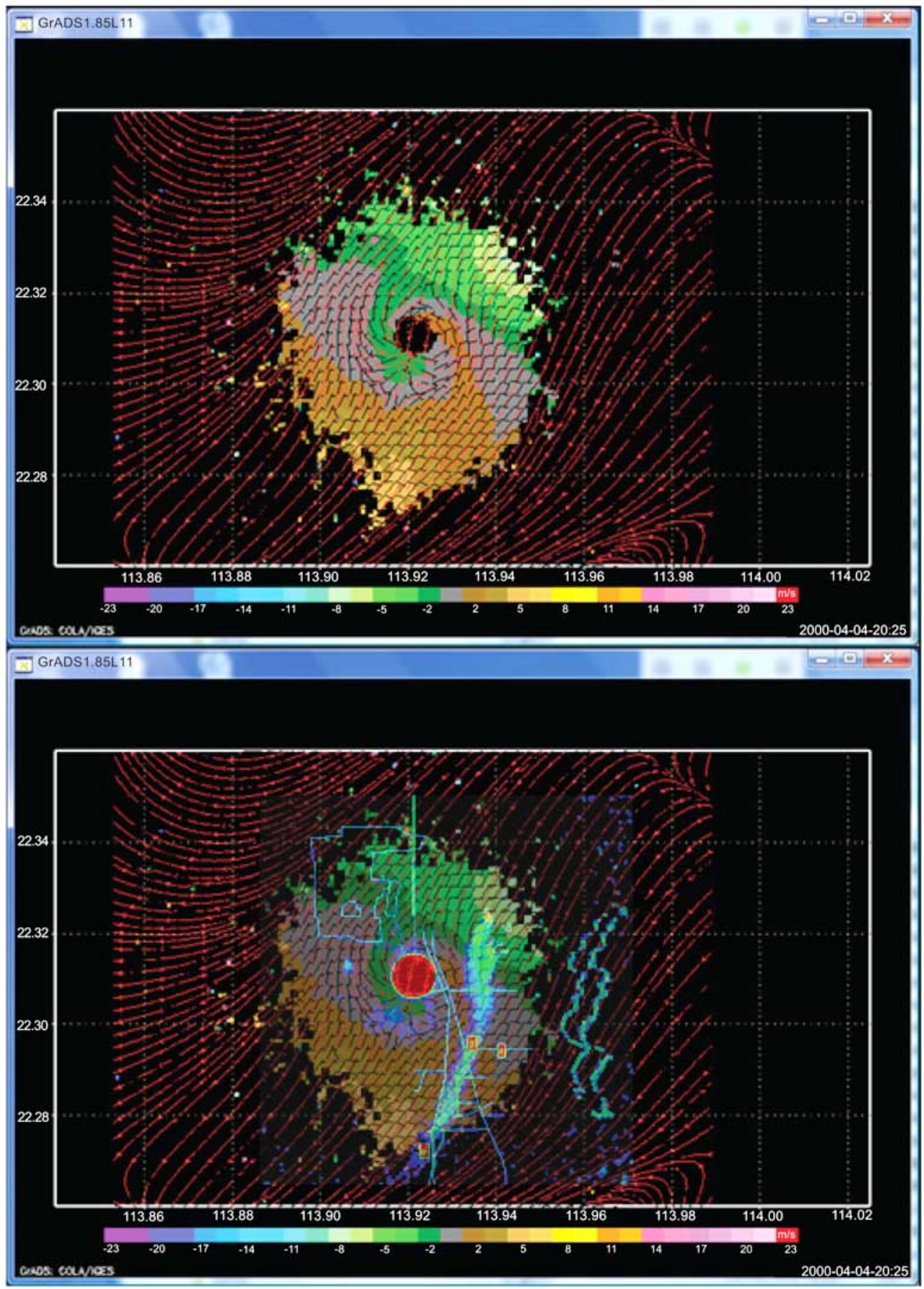

5:29am, 29 ${ }^{\text {th }}$ August 
(Fig. 7) contd.....

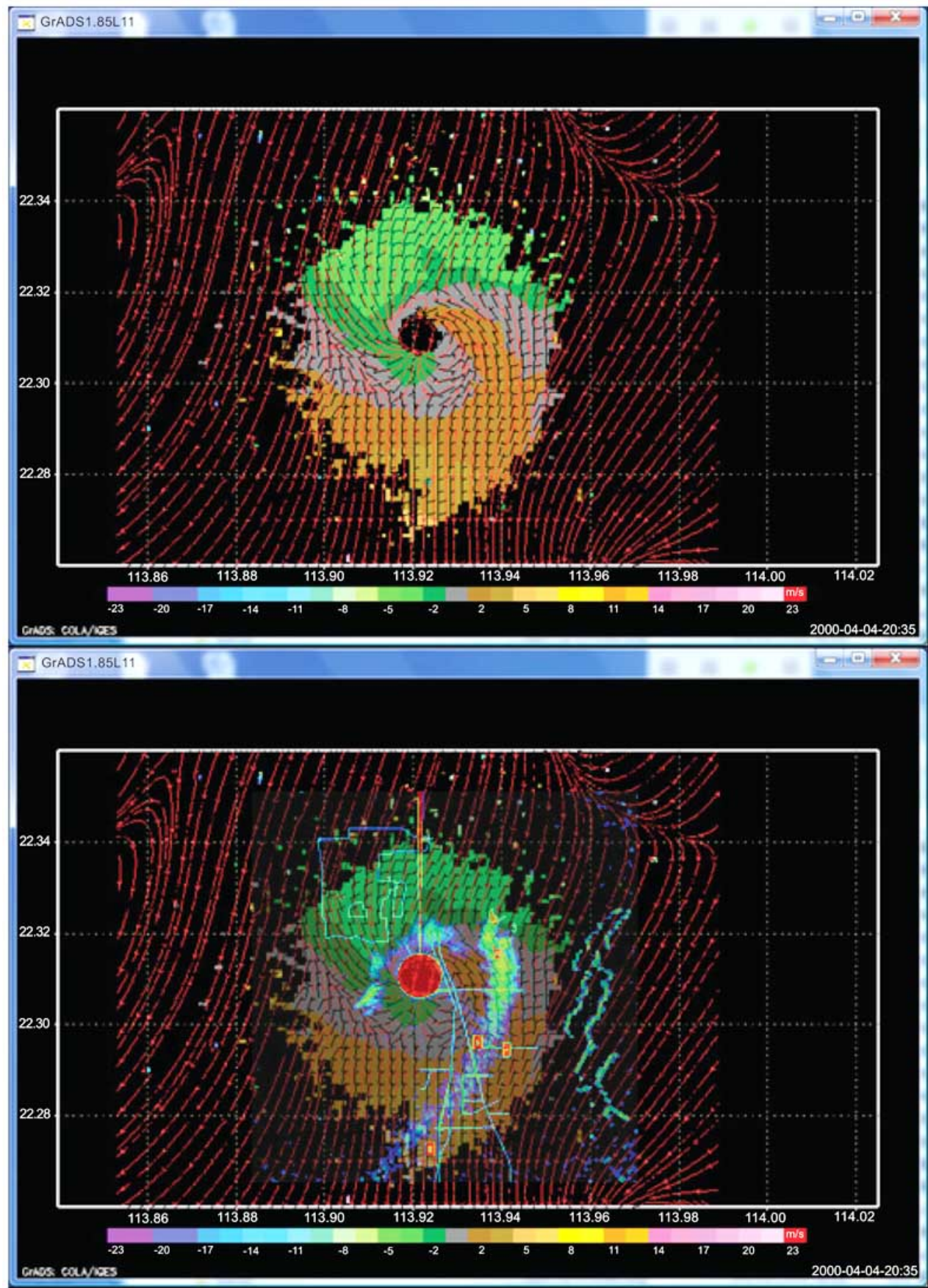

5:50am, 29 ${ }^{\text {th }}$ August

Fig. (7). Same as Fig. (6) but on $29^{\text {th }}$ August 2006. 


\section{NOx measurements / 18 Aug 2006}
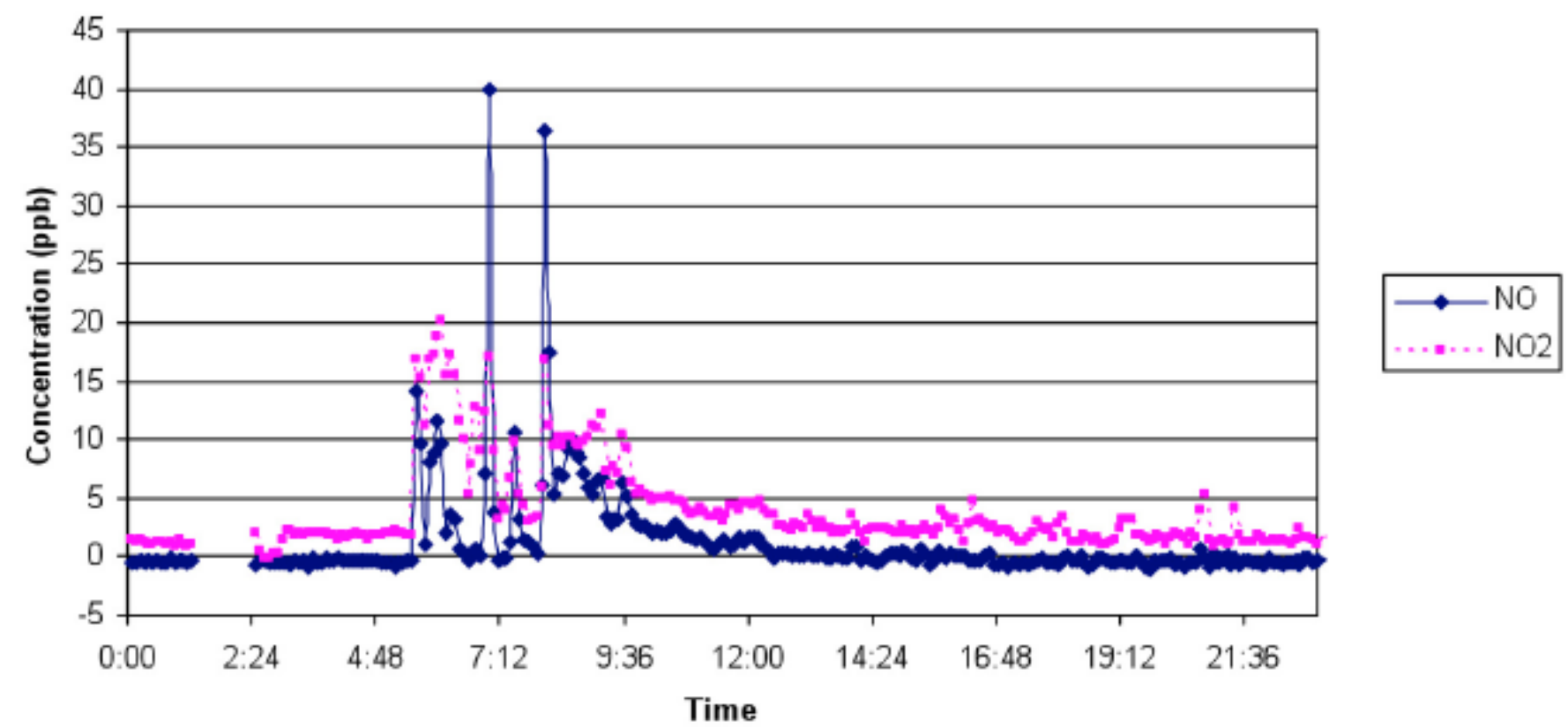

NOx measurements I 29 Aug 2006

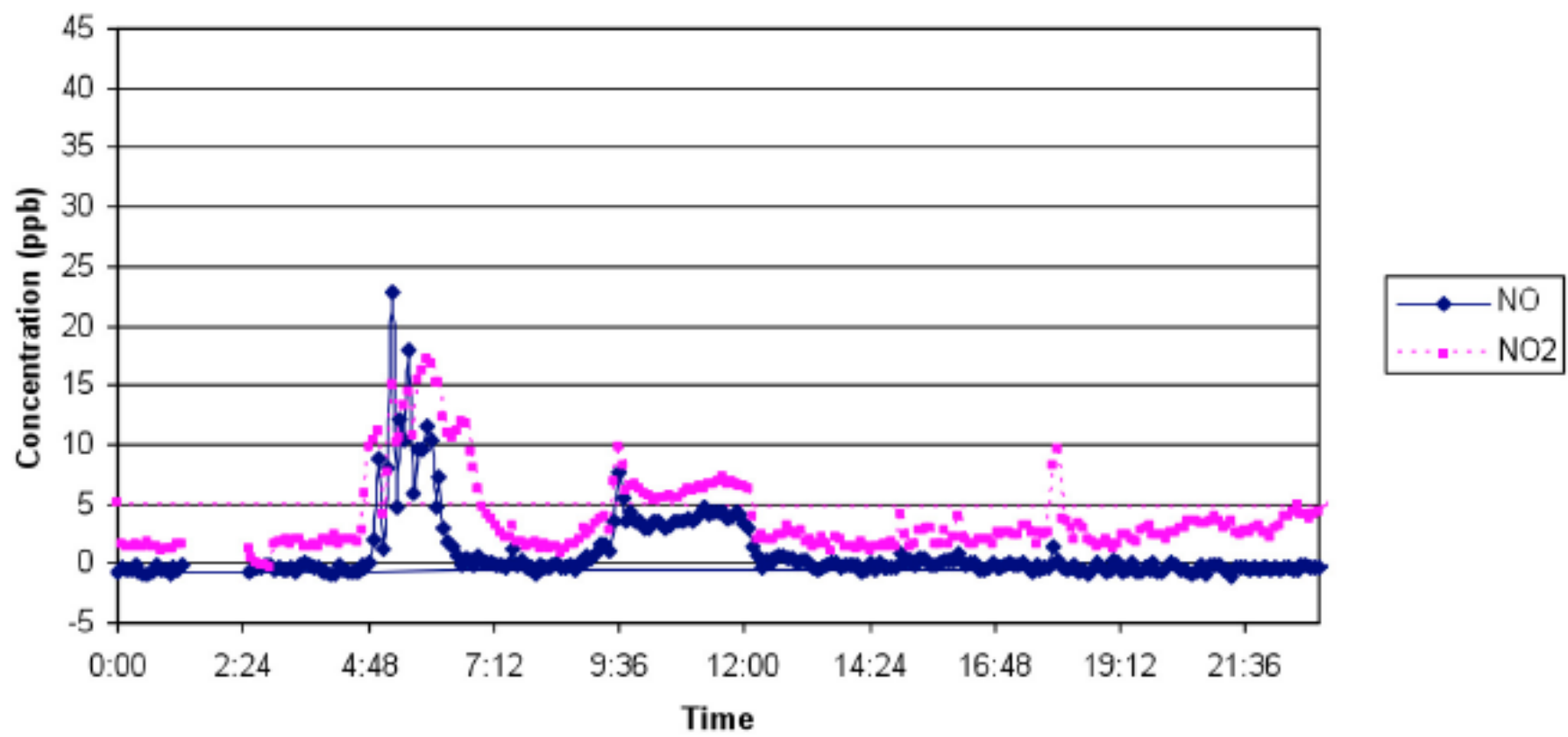

Fig. (8). NOx measurements on both $18^{\text {th }}$ and $29^{\text {th }}$ August 2006.

\section{CONCLUSIONS}

The 2D wind retrieval algorithm has demonstrated its capability in providing useful 2D wind vector field based on LIDAR data for assisting the monitoring of smoke plumes and the determination of the related dispersion mechanism. The wind changes in the lower part of the atmospheric boundary layer are readily visualized in the $2 \mathrm{D}$ wind field as presented in the above two cases. Future works are suggested to quantify the deviations between 2D retrieved wind vectors and the anemometer measurements if the spatial and time averaging differences in the measurement can be reduced. It will also be useful to expand the ability of the $2 \mathrm{D}$ wind retrieval algorithm to analyze each layer of the volume LIDAR scan (at several elevation angles) acquired by different scanning patterns to understand the 3D wind structures.

\section{ACKNOWLEDGEMENT}

The authors would like to thank Professor Chong-jian Qiu of Lanzhou University for providing the 2D wind retrieval code for the LIDAR. 


\section{REFERENCES}

[1] Chan PW, Shao AM. Depiction of complex airflow near Hong Kong international airport using a doppler LIDAR with a twodimensional wind retrieval technique. Meteorol Zeitsch 2007; 16: 491-504.

[2] Chai T, Lin CL, Newsom RK. Retrieval of microscale flow structures from high resolution doppler lidar using an adjoint model. J Atmos Sci 2004: 61: 1500-20.
[3] Newsom RK, Banta RM. Assimilating coherent doppler lidar measurements into a model of the atmospheric boundary layer. Part I: algorithm development and sensitivity to measurement error. J Atmos Ocean Tech 2004; 21: 1328-45.

[4] Qiu C-J, Shao AM, Liu S, Xu Q. A two-step variational method for three-dimensional wind retrieval from single doppler radar. Meteorol Atmos Phys 2006: 91: 1-8

Received: August 15, 2009

Revised: November 14, 2009

Accepted: January 27, 2010

(C) Chan and Yu; Licensee Bentham Open.

This is an open access article licensed under the terms of the Creative Commons Attribution Non-Commercial License (http://creativecommons.org/licenses/bync/3.0/) which permits unrestricted, non-commercial use, distribution and reproduction in any medium, provided the work is properly cited. 